\title{
A MICROPYROMETER
}

\author{
By George K. Burgess
}

Some time ago a method was described ${ }^{1}$ suitable for the rapid estimation of the melting points of minute specimens-as fine as o.oor milligrams or less. A microscope and an optical pyrometer were sighted through a window of mica, or of plate glass (in case of melts in vacuo), simultaneously on an inclosed metallic strip, such as platinum, heated electrically, and upon which was placed the specimen to be melted.

Evidently this apparatus may be simplified by combining microscope and pyrometer into a single instrument, thus permitting a single observer to watch the melting and measure its temperature. This is effected by mounting within the Huyghens eyepiece of an ordinary microscope a small incandescent lamp, which is in series with a rheostat and ammeter. The tip of the filament of the lamp is set to the same brightness as the platinum strip viewed from above at the instant of melting of the metallic or other specimen on which the microscope is focused. The eye of the observer, therefore, sees the specimen, the platinum strip, and the lamp filament all in focus at once, and the current through the lamp is taken as a measure of the temperature of the strip as in the Morse or Holborn-Kurlbaum pyrometer. In practice, the observer with one hand raises the temperature of the platinum strip by increasing the electric current through it by means of a fine-step rheostat and with the other hand adjusts the rheostat in the pyrometer circuit so as to continuously match in brightness the lamp filament and platinum strip. The eyepiece is furnished with a piece of monochromatic glass, such as Jena red filter No. F 4512. For temperatures above which the lamp should not be burned, say

G. K. Burgess: Melting Points of the Iron Grcup Elements by a New Radiation Method, Bull. Bureau of Standardis, 8, p. 345; 1907. 


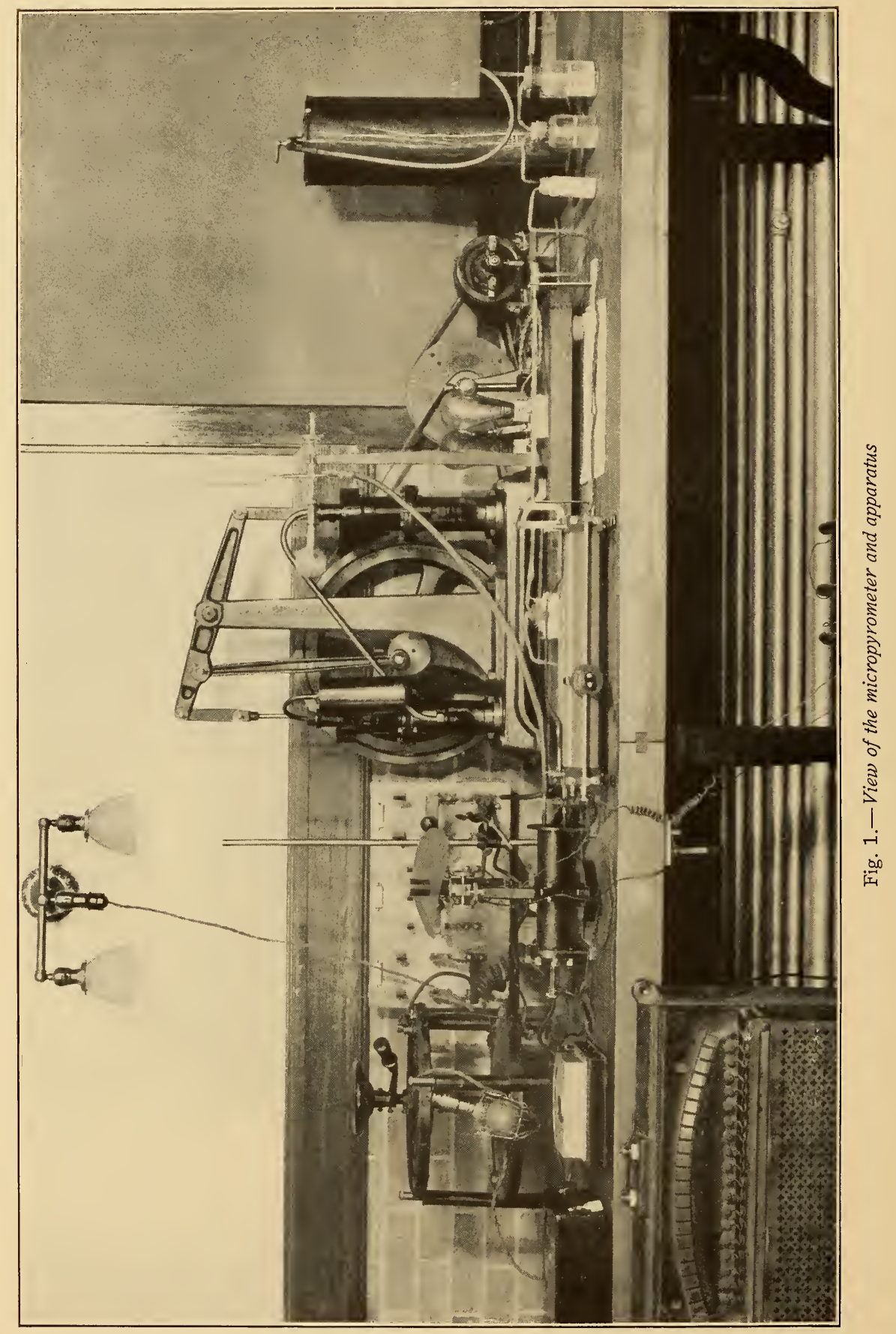


$1400^{\circ} \mathrm{C}$, an absorption glass is placed between the microscope objective and furnace window. The inside of the metallic container or furnace should be blackened to prevent undesirable reflections of light from the walls.

The calibration of the pyrometer as sighted upon the platinum strip in the furnace may be made in two ways. The first, which was the only method available when the earlier form of this apparatus was brought out, due to the dearth of well-known fixed points in the temperature range studied, consists in calibrating the pyrometer in the customary manner and then applying the corrections at the temperatures of melting for the emissivity of platinum, furnace atmosphere, and window, and for the surface tension of the melting specimens when necessary.

The second method, which appears to be the more accurate and also more convenient, consists in observing the lamp currents at the known melting points of two or more pure substances, such as gold, nickel, cobalt, and palladium, and from the equation expressing the relation between temperature and current in lamp the temperature of melting of any specimen may be computed. For not too great temperature intervals we may use the equation $\log c=a+b \log t$, which permits calibration with two fixed points only.

This second method of calibration has the further advantage that, for materials of approximately the same general properties, the error of method is eliminated. Thus, in the case of metals which alloy with platinum, the effects of alloying, conductivity, and of surface tension enter into the calibration as well as into the determination of the unknown melting point, so that any outstanding error will be but a residual one. In the case of substances of dissimilar properties, such as salts and metals, this apparatus must be used with caution, for, in general, a calibration made in terms of the metal melting points, for example, will not serve for the exact determination of the melting points of salts.

The precision of the method is dependent mainly upon the character of the melting of the substances observed. With metals such as gold and nickel, which melt very sharply, a precision of $\mathrm{I}^{\circ}$ or $2^{\circ} \mathrm{C}$ is obtainable. 


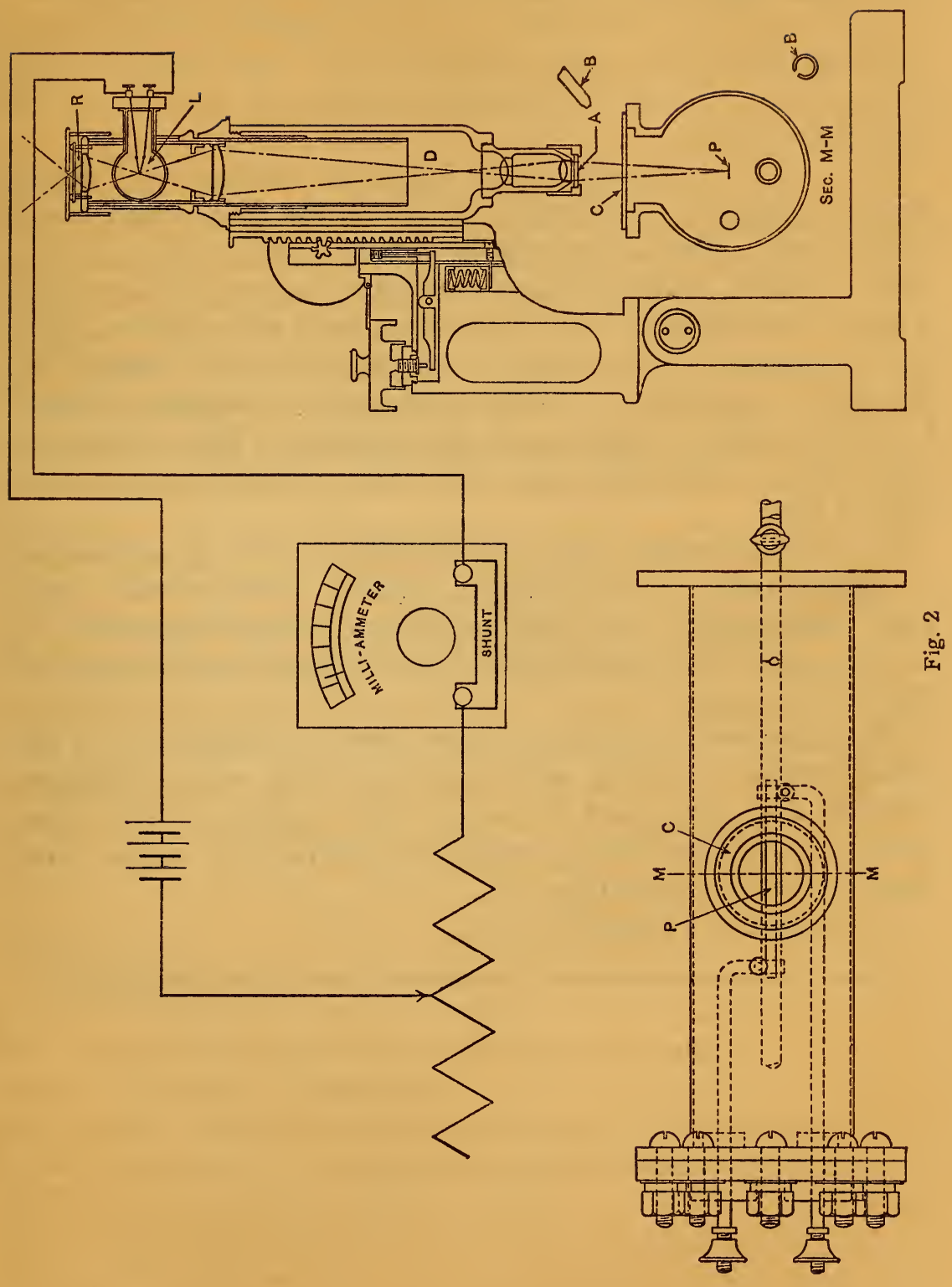


The apparatus as constructed at the Bureau of Standards, largely from suggestions due to Messrs. Crowe and Foote, of this Bureau, is shown in Fig. 2, in which $L$ is the pyrometer lamp, $R$ the monochromatic glass, $\mathrm{A}$ the absorption glass, $\mathrm{P}$ the platinum strip carrying the specimen, $\mathrm{C}$ the furnace window, $\mathrm{B}$ an air blast for cooling the surface.

Fig. $I$ is a photograph of the apparatus arranged for taking melting points in a hydrogen vacuum. The microscope has a Bausch and Lomb 48-mm single achromatic lens and $6.4 \mathrm{x}$ eyepiece and gives sufficiently good definition and magnification and a large enough field of view for melting point observations. The working distance of the objective may be increased, if desired, by the device employed by Robin ${ }^{2}$ of inserting. a biconcave lens at $\mathrm{D}$, slightly back of the focus of the objective. This necessitates lengthening considerably the draw-tube and reduces the area sighted upon.

The micropyrometer may, of course, be used for the estimation of temperatures of incandescent surfaces simultaneously with their examination, and thus becomes a useful instrument in metallographic and microchemical and physical investigations at high temperatures.

The apparatus is being used at the Bureau of Standards for the determination of melting points and emissivities of the refractory elements and alloys, and the author will be glad to receive pure samples (a few hundredths milligram), particularly of the rarer elements for such determinations.

Washington, December 9, I 912.

${ }^{2}$ F. Robin: Microscope à longue portée etc., Bull de la Société d'Encouragement, 118; p. 204; 1912. 